\title{
Ignacio Ellacuría, 20 años después
}

\author{
Manuel Mazón, \\ Universidad Centroamericana "José Simeón Cañas", \\ San Salvador.
}

\section{Introducción}

Estuve sentado al lado de Ignacio Ellacuría en su última sesión del Seminario Zubiri de Madrid. Después de tanto tiempo y sobre todo por lo acaecido días después, sólo recuerdo que me invitó a venir a trabajar a la UCA. Le hice una promesa que pude cumplir a partir de 1992, desgraciadamente ya sin su compañía y dirección intelectual. Hoy quiero hacerle un pequeño homenaje a través de esta su tan querida Revista Latinoamericana de Teología.

He estado dudando si usar la fórmula literaria, que tanto gustó y sigue alumbrando las mentes filosóficas, del diálogo platónico para traer a primer plano lo más recóndito que controla y realmente oprime a la mente en su deseo radical de liberarse y de mejor conducirse entre las cosas y las vicisitudes de la existencia. Pero me he decidido por algo todavía más griego que hace referencia a los grandes poemas homéricos, lo que, usando la fórmula latina, responde al irruit in medias res. Es entrarle a la cuestión justo ahí in medias res, al núcleo de lo que se quiere poner de manifiesto.

José Luis López Aranguren, gran catedrático de Ética en la Universidad Complutense de Madrid, fue un luchador infatigable desde su cátedra por las libertades ciudadanas en los tiempos difíciles del franquismo, tan así que dicha cátedra le fue arrebatada por la administración pública en 1968, a sus muy largos 50 años. Pues bien, en cierta ocasión Aranguren le había dicho a Ellacuría: "usted ha hecho de Zubiri un guerrillero".

1. Citado por Antonio González en la conferencia pronunciada en el Círculo de Bellas Artes (Madrid), el 16 de noviembre de 2004. Recogida en la obra Vascos universales del siglo XX. Juan Larrea e Ignacio Ellacuría, Biblioteca Nueva, 2005, p. 208. 
Zubiri solía decir que la filosofía, si era algo, era libertad. Y ante todo libertad como liberación. En su última intervención en público, con motivo de la presentación de sus libros Inteligencia y Logos e Inteligencia y Razón, nos dejó la confidencia vital sobre su trayectoria en el esfuerzo continuado por liberar a su pensamiento de las propias oscuridades, como al encadenado de la Caverna de Platón. Era el 31 de enero de 1983. Éstas fueron sus palabras, y allí y en primera fila estaba Ellacuría: "Mi vida intelectual - dijo - ha discurrido como una corriente bordeada y encauzada por dos riberas: una, la de liberar el concepto de realidad de su adscripción a la sustancia. Las cosas reales no son sustancias sino sustantividades, no son sujetos sustanciales sino sistemas sustantivos. De ello me ocupé en mi libro Sobre la esencia. La otra ribera es la de liberar la intelección, la inteligencia, de la adscripción a la función de juzgar. Se nos decía que lo que no sea juzgar es sólo tener ideas, y que ideas se pueden tener muchas, pero solamente el juicio que afirma es el que pretende decirnos lo que realmente es la cosa sobre la que se afirma. Eso me parecía - y me sigue pareciendo- una ingente insuficiencia. No porque no sea verdad que el juicio sea una función de inteligir; esto es verdad. Lo que no es verdad es que inteligir sea esencialmente juzgar. Esto no, en absoluto. Lo primario es la aprehensión primordial de realidad, el tener impresión de realidad de las cosas. Esta aprehensión primordial de realidad es justamente la forma primaria y real con que la inteligencia accede a lo real. El acto formal de la intelección no es el juicio sino que es la aprehensión de la cosa real misma. Y esa cosa misma se nos da primaria y formalmente en la aprehensión sensible, esto es, en la impresión de realidad. Por lo que tiene de impresión es sentiente. Por lo que tiene de realidad es intelectiva, puesto que la inteligencia intelige formalmente lo que es la realidad. Por consiguiente, tener impresión de realidad es tener un acto de inteligencia sentiente. A mi modo de ver, esa liberación del juicio era crucial para poder, por lo menos para mí personalmente, ponerme en marcha en materia filosófica"”.

En la encrucijada de esta tensión intelectual adquiere toda su fuerza la tarea de Ignacio Ellacuría desde 1962, cuando, como se sabe, contacta con Zubiri, y ya no se apartará de la dirección intelectiva de su pensamiento hasta su muerte violenta en 1989. Dejando a un lado lo anecdótico como tal, por lo que tiene la expresión de "guerrillero" aplicada a la lucha del pensamiento, sí es verdad que Ellacuría toma su fuerza mental de esta encrucijada, descrita por Zubiri de su gigantomaquia personal en su tarea intelectual que le ocupó sin concesiones a ningún tipo de actividad pública hasta el término de su vida a sus 83 años.

Ignacio Ellacuría trabaja su tesis doctoral, como es sabido, con Zubiri precisamente, sobre la obra de Sobre la esencia. Creo no exagerar si afirmo que nadie como él penetró con la intencionalidad del propio Zubiri en lo que entiendo es

2. Recogido en X. Zubiri, Escritos Menores (1953-1983), Alianza Editorial, Madrid, 2007. 
lo más arcano de esta obra: lo que tienen de real las cosas es su esencia y ésta como el principio desde y en el que la mente humana intentará siempre arrancar algunas "esquirlas de inteligibilidad"3 a todo aquello que se nos presenta como siendo o que quiere llegar a ser.

Cada persona sigue ya su propia inspiración vital como una $\mu \alpha v i ́ \alpha$ (especie de deseo incontenible), en expresión griega acuñada por Platón, para indicar la direccionalidad filosófica de cada cual. Ellacuría, en su opción religiosa radical y pública, supo concretar en la formulación jesuítica de "el servicio de la fe y la promoción de la justicia" y en su modalidad liberadora de "la opción por los pobres" - inspirada su expresión de implantar una civilización de la pobreza como alternativa a la actual civilización de la riqueza y el consumo-, supo canalizar, digo, toda la fuerza que la mente experimenta cuando se deja poseer por la verdad que el saber filosófico va descubriendo.

Ellacuría se polarizó intelectualmente hacia una Filosofía primera, buscando sentir la impresión primordial de la realidad histórica, y hacia la complejidad de una Teología política que arrancara a "las mayorías populares" de la opresión en la que las sumen la miseria, el poder de las oligarquías económicas y la ilusión mítica de ideologías que a la postre solo se alimentan de su propia dialéctica. Desde esta perspectiva o situación intelectual, me gustaría ofrecer simbólicamente a Ignacio Ellacuría una muestra de primacía editorial de algo que seguramente él nunca pudo tener en las manos, y ello paradójicamente porque estos archivos fueron descubiertos bastante después de su muerte.

En los 25 largos años que Ellacuría tuvo trato con Zubiri, fue su gran animador en la producción de su obra filosófica. Fue testigo de esa sistematización zubiriana de una nueva categoría desde la que poder desarrollar eso que llamaba "la congenereidad de inteligencia y realidad"4. Es la categoría de actualidad de realidad ese modo de quedar las cosas ante la mente como algo en propio, algo de suyo, algo que me afecta como otro y se me impone con toda la fuerza de exigir una respuesta o buscarla, si actualmente no la tuviere "a la mano" (en expresión heideggeriana).

De esa radicalidad del sentir humano arranca la opción de hacerse cargo de la propia realidad. Este fue el secreto intelectual de Ignacio Ellacuría, su guía en el discurso ceñido de su mente filosófica, teológica y política. Pues bien, siempre tuvo clara la enseñanza de su maestro Zubiri.

Hay una lógica de la realidad y hay una realidad que se categoriza radicalmente no como sustancia, sino como estructura, que llamó sustantividad, cuya construcción hace posible a la mente humana ir formulando saberes que la acer-

3. Expresión zubiriana en el prólogo de Inteligencia y Realidad (IRE), Madrid, 1980.

4. Del mismo prólogo de Inteligencia y Realidad. 
can más y más a la verdad. Siempre la cercanía a la verdad de la realidad. Implantarse, aunque sea muy provisionalmente, en la realidad verdadera. Intentar mantener siempre la búsqueda de lo que me reclama para ser descubierto.

Esa es la fuerza de imposición de la realidad. Ahí se "alumbra" la marcha del ser humano en la tarea de hacerse la vida. Ahí se va manifestando la expresión solidaria que aparece en "la justeza" que da sentido a la comunidad de los distintos pueblos que hasta nosotros han llegado, y en "las formas y modos de vida" que nos han transmitido. Ellacuría, como buen discípulo de Zubiri, sabía que para ello era ineludible - valores religiosos y de otra índole aparte- el descubrimiento intelectual de una lógica siempre renovada de la realidad y una arquitectura intelectual que mantuviera el cañamazo (expresión zubiriana) de la marcha de la razón en tensión hacia la verdad siempre por descubrir.

El descubrimiento mismo de una lógica de la realidad conlleva la luz intelectual sobre la categorización de esa misma realidad desde otro parámetro ya distinto del de la sustancia (la oủoía griega). Más o menos tendría sus treinta y tres años Ellacuría cuando conoció a Zubiri. Cuando éste tenía esa misma edad, era un joven catedrático de la Universidad de Madrid, allá por los años de 1931 a 1935. Por fortuna, he podido tener la confianza de los actuales directores de la Fundación Xavier Zubiri de Madrid para investigar durante los últimos años de mi vida universitaria madrileña en la posible reconstrucción de ese período de la vida filosófica de Zubiri. Era la época de la República española, que como se sabe desembocó en una muy cruenta guerra civil de tres años que dio al traste con tantas realidades y proyectos de tipo intelectual en general, y en particular por lo que se refiere a la vida y obra de Xavier Zubiri.

Rebuscando por archivos que se daban por perdidos, he podido reconstruir algo que hubiera llenado de asombro a nuestro Ellacuría, al comprobar cómo esa investigación nos ha desvelado la inquietud de Zubiri transmitida como experiencia intelectual primigenia para aquellos alumnos y alumnas que comenzaban entonces su carrera de filosofía. Aquellas exposiciones llevaban en sí, a modo de inquietante tanteo, lo que andando los años daría como fruto la obra ingente del filósofo español.

He pensado que constituye un buen homenaje en recuerdo de Ignacio Ellacuría reproducir aquí dos fragmentos hoy todavía inéditos, pero que en breve verán la publicidad editorial ${ }^{5}$. Refiérese el primero al curso que Zubiri dio en el período escolar 1935-36 sobre "Fundamentos de lógica". Y el segundo, al curso

5. Toda esta investigación está contenida en cuatro volúmenes, bajo el título de Xavier Zubiri. Cursos Universitarios. El volumen I ya fue editado en 2007 (Alianza Editorial, Madrid). Está a punto de salir, en este 2009, el volumen II. Y los dos restantes, esperemos que en los dos años sucesivos. Estos dos fragmentos pertenecen, el primero al volumen IV, y el segundo al volumen II. 
sobre "Categorías filosóficas" impartido en seis conferencias en la Universidad de Verano de Santander en 1933.

$$
* * *
$$

\section{Del primer inédito: Fundamentos de lógica (1935)}

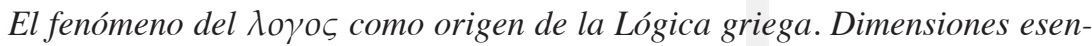
ciales del $\lambda \dot{\varepsilon} \gamma \varepsilon \iota v$ que determinan el nacimiento de una "lógica”, y que perduran en toda lógica a través de la Historia de la Filosofía:

Sin hacernos cuestión del origen de la Filosofía, indicábamos simplemente, a grandes rasgos en la última lección unos cuantos tipos representativos de las diferentes maneras como el filósofo ha surgido en la Historia, cuyas características, en una u otra forma, han perdurado en la Filosofía. Y colocados en este punto de vista, y supuesto que efectivamente estamos haciendo Filosofía, la dificultad máxima y la tarea capital no estriba, en contar, meramente, lo que la Filosofía ha dicho en cada caso, sino en hacer emerger los sistemas filosóficos de las cosas de que son teoría. Como punto de partida inicial tomábamos el modo cómo el hombre entra en el Universo hablando, entra el hombre en el Universo dotado de un $\lambda$ ó $\gamma$ os en virtud del cual se constituye como un ente distinto de todos los demás; de aquí que la Filosofía griega haya comenzado con el intento de ser una estricta $\gamma \varepsilon v \varepsilon \alpha \lambda$ oүí $\alpha$, un dar el hombre razón de su $\gamma \varepsilon \dot{v}$ os. Intentaremos, pues, ver qué es el hombre en tanto que tiene un $\lambda$ ó $\gamma \circ \varsigma$, para asistir a la constitución de la "Lógica".

Hemos de salir al encuentro del grave peligro que podría correr la Filosofía en general si se creyera que en la Historia de la Filosofía se trata solamente de "referir teorías", limitándonos a la faena de enterarnos de las filosofías de los demás. No es esto lo único que hay que hacer. Es preciso informarse de las teorías, pero esto implica y supone el esfuerzo intelectual de ver emerger las teorías de las cosas. La apelación a las teorías filosóficas envuelve un ver nacer las teorías de las dimensiones reales de las cosas: un hacer que hablen las cosas. Con este intento vamos a aproximarnos al fenómeno del $\lambda \dot{\varepsilon} \gamma \varepsilon \mathrm{\iota}$. El hombre ha entrado en el Universo hablando, y sería un error creer que el $\lambda$ ó $\gamma \mathrm{O}$ consiste primariamente en un razonar, o razón.

Contra la interpretación corriente de esta palabra como "razón" o "ciencia",

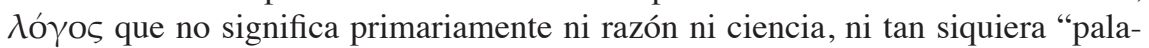
bra". Lo fundamental en el $\lambda$ ó $\gamma O \varsigma$ es algo distinto de todo esto: el "hablar" de

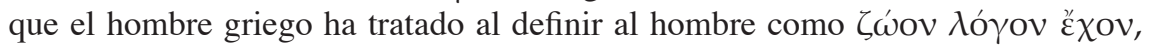
en primer lugar, supone o implica que, en una u otra forma, el hombre va a las cosas. Este ir del hombre a las cosas no es tan sencillo de entender como pudiera parecer; nos parece obvio que el hombre vaya a las cosas, puesto que constitutivamente se encuentra entre ellas; pero, ¿qué sentido tiene que el hombre

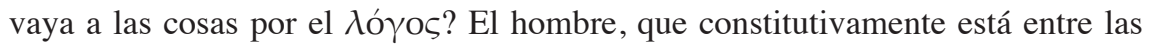


cosas, puede hallarse entre ellas de dos modos distintos: de un modo latente, y de un modo patente.

En el primer caso, las cosas no le son manifiestas de una manera clara, como

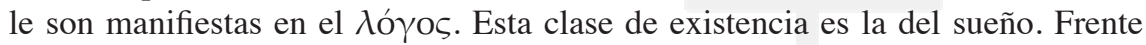
a esto, el hombre despierto está entre las cosas y va a las cosas de una manera distinta. La mayor parte de los hombres, dice Heráclito, se encuentran entre las cosas como dormidos; el modo de existencia patente del hombre entre las cosas es un despertar de una especie de letargo profundo, en que el hombre vive como muerto, ya que el griego ha interpretado la muerte como cierto sueño póstumo a la vida, igual al sueño que precedió también al comienzo de ella. El hecho, la facticidad que acontece con este despertar del hombre a las cosas, consiste en que para los hombres en estado de vigilia no hay más que un mundo, común a todos ellos, mientras que cada durmiente tiene su propio mundo. Este carácter

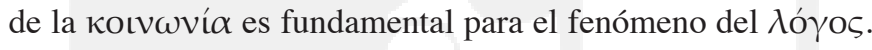

Segundo momento esencial del $\lambda o ́ \gamma o s$. Sería un error creer que en este despertar a las cosas, el $\lambda$ ó $\gamma o \varsigma$, que empieza por ser una exclamación, es sólo eso,

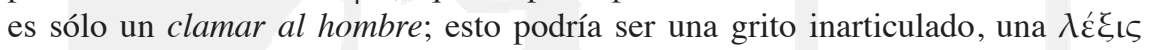
en todo caso, pero nunca un $\lambda$ ó $\gamma$ os; cuando el hombre habla, no es propiamente él quien habla, sino que, en una u otra forma, realiza aquello cuyo sentido conserva la espléndida expresión española, "hacer hablar a las cosas". Y en la medida en que el hombre "hace hablar a las cosas", discierne el sueño de la vigilia. El mundo común de la vigilia imprime a ésta el sello de su autenticidad. En el $\lambda$ ó́os experimenta el hombre esa especie de voz íntima por la cual se declaran las cosas, y que constituye al hombre en estado de vigilia.

Por eso, en tercer lugar, es preciso no perder de vista que lo que constituye al hombre en su estado de vigilia es el escuchar la voz de las cosas, mediante el vocĩv, el voũs, o mens en latín. El hombre dormido carece de mens, es "amente"; y el hombre "demente" es el que, en estado de vigilia, no deja hablar

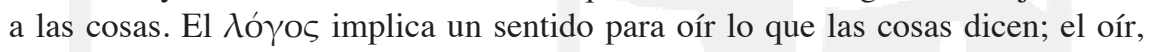

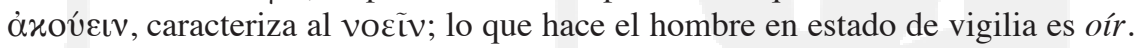

En cuarto lugar, cuando el hombre tiene mente, oye lo que le dicen las cosas, y dice lo que escucha de ellas: dice la verdad. Es cierto que también en este

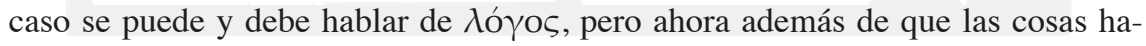
blan, habla el hombre conforme a las cosas. Hemos dicho que el voũs es para un griego un escuchar lo que las cosas dicen. Este "decir" es una acción de las cosas, pero una acción "sui generis"; en el caso de la luz, por ejemplo, no consiste en la acción de iluminar, ni en el caso del fuego en calentar. Es una acción especial en virtud de la cual las cosas dejan oír lo que son. En esta duplicidad en virtud de la cual las cosas son lo que son y además dicen lo que son, consiste la verdad de las cosas, su $\alpha \dot{\alpha}-\lambda \eta ́ \theta \varepsilon \iota \alpha$; las cosas, en su virtud, no son sólo fenómenos, sino "verdades". Decir la verdad es entregarse a este escuchar. 
En quinto lugar, esta entrega a las cosas implica un sentido íntimo para oír su voz. Por el oír el hombre está, como diría un griego, en $\alpha$ Quoví $\alpha$ con las cosas, al unísono con ellas. Heráclito dice que, por mucho que el hombre se empeñe,

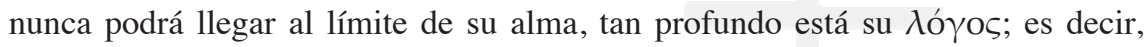
tan profunda es su naturaleza en cuanto refleja lo que son las cosas. Este sentido del $\lambda o ́ \gamma o s$ perdurará en la Filosofía medieval en la idea de la "sindéresis" y en la "scintilla animae" de los místicos. El бoфós, el sabio, es el que escucha la voz íntima de las cosas en su ser.

He ahí algunos caracteres esenciales del $\lambda o ́ \gamma o \varsigma$, lo suficientemente primarios para que no hayan dejado nunca de existir. Supuesto, pues, que el hombre, como animal racional, tiene $\lambda$ ó $\gamma$ os, participa de todo esto. Es preciso ver ahora con claridad algunos de estos caracteres esenciales. Cuando escuchamos la voz de las cosas, la audición de ella es una entrega al sentido íntimo que nos manifiesta la cosa haciéndole justicia; se trata de un pronunciamiento acerca de la verdad de las cosas, de un dictamen, o fallo que es una función declarativa en que el

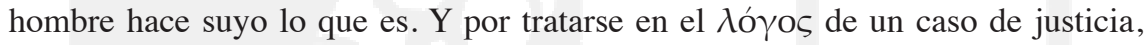
o de fallo, su primer carácter es el de justicia o rectitud: una recta entrega a la

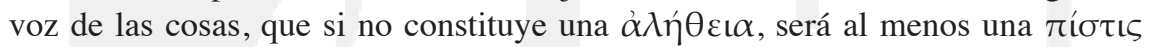
$\dot{\alpha} \lambda \eta \theta \eta \dot{s}$, es el que dice lo que es de acuerdo con lo que oye y siente, siendo el $\lambda o ́ \gamma O \varsigma$ humano, en virtud de este sentido de justicia, un k@íveı v, un discernir.

Algunos fragmentos de Parménides ponen en claro estos diversos caracteres del $\lambda o ́ \gamma o s$, que son a la vez los fenómenos fundamentales de toda Lógica en general. En el fragmento primero se nos relata el rapto de Parménides a un mundo más allá del mundo en que habitamos, donde la Diosa, después de descorrer un velo, le revela lo que es la verdad, diciéndole al mismo tiempo: "el Derecho y la Justicia te han enviado por este camino". "Es conveniente que aprendas todas las cosas, tanto el inconmovible corazón de la bien redondeada verdad como las opiniones de los mortales en las que no hay $\pi \dot{i} \sigma \tau \iota \varsigma \alpha \hat{\alpha} \lambda \theta \eta \dot{\eta} \varsigma$ ". "Refrena tu mirada, tu oído y tu lengua, y discierne por el $\lambda$ ó $\gamma 0 \varsigma$ ”. Es preciso completar esto con fragmentos de Heráclito en que aparece el $\lambda$ ó $\mathrm{O}$ S como un sentir que lleva con-

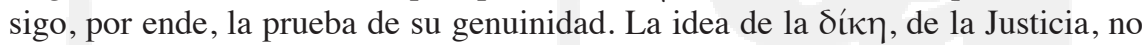
es aquí sino la justicia con que el hombre "hace justicia" a las cosas. Las cosas tienen una voz justa, que Heráclito llama $\lambda o ́ \gamma o \varsigma$, que es preciso oír y reflejar, si bien no todos, sino muy pocos, los ooфoí, los oráculos, son capaces de oír esta voz. El oráculo de Delfos es para Heráclito el prototipo del ooфós.

La sabiduría consiste para Heráclito en escuchar esa voz interior, en tener dentro el $\lambda o ́ \gamma o \varsigma$ de las cosas; el carácter primero de la бoфía es una

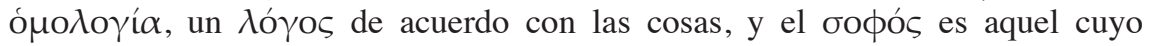
$\lambda o ́ \gamma o \varsigma$ enuncia la voz de las cosas, su justicia, ni más ni menos que lo que son las cosas con su $\mu$ ćt@ov. Las cosas son cosas que se sienten y se palpan, y su voz les es constitutiva. Heráclito nos dice en el fragmento primero, que los 


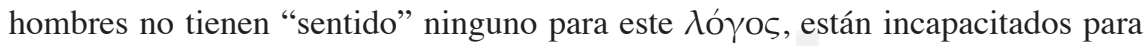
entenderlo, como si estuvieran dormidos. "Es deber de todo hombre sentir tò

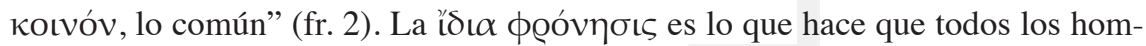
bres estén dormidos. La idea del $\lambda o ́ \gamma 0 \varsigma$ como cimiento del alma se encuentra en el fragmento 45: "De tal manera es abismal la voz interna por la cual el hombre refleja las cosas". Esta misma idea en otra forma aparece en el fragmento 115. Y en el fragmento 112 se nos dice que la virtud de los mejores consiste en decir la verdad, y que el que hace bien las cosas es el que las hace conforme a la verdad.

Veremos en lecciones sucesivas cómo de estos caracteres primarios del $\lambda o ́ \gamma o s$ ha emergido de una manera radicalmente filosófica toda la Lógica griega,

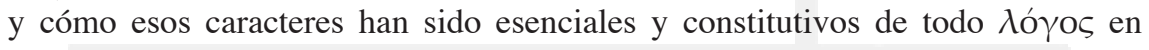
general.

\section{Articulación de la esencia y la cosa}

$1^{\circ}$. La esencia de una cosa no es una segunda cosa yuxtapuesta a la primera. Si fuera así, esto no haría sino desplazar el problema. La esencia no está metida dentro de la cosa. Considerar la esencia como una cosa, la cosa esencial, es algo obvio.

Es posible hablar del "meollo" de las cosas, ser esencia. Y a pesar de todo el esfuerzo de Aristóteles, el pueblo griego no ha sabido liberarse de esta idea según la cual, la esencia de una cosa es la cosa esencial de ella. Pero no, la esencia no es una segunda cosa, por lo menos no es una cosa como la primera. La esencia no es cosa, sino esencia de la cosa. Dando a la palabra $\gamma \varepsilon ́$ vos un sentido amplio, no exclusivamente "género", podemos decir que la esencia es siempre esencia "de", es el carácter genitivo o generativo de la esencia. Nunca puede ser nominativa. Sólo la cosa es nominativa.

$2^{\circ}$. Hay que interpretar rectamente esta genitividad de la esencia. Pudiera creerse que es por aditamento extrínseco. Tratándose de cosas se entiende que lo que engendra existe antes de engendrar; el carácter genitivo de las cosas es consecutivo a ellas. No así en la esencia. La genitividad no es consecutiva sino constitutiva de la esencia. Ser esencia es estar esenciando. Todo el modo de ser del vino es ser todo de vino, ninguna esencia puede reposar en sí sin especificar los individuos. La esencia qua esencia es genitiva.

$3^{\circ}$. La esencia está toda en toda la cosa. La esencia afecta a la totalidad de la cosa. [No es que no pueda plantearse el problema de si puede prescindirse de algo que es en la cosa sin que deje ésta de ser lo que es. Se puede ser manco y ser hombre. Pero esto lo veremos más tarde. Por eso Aristóteles tuvo que escri-

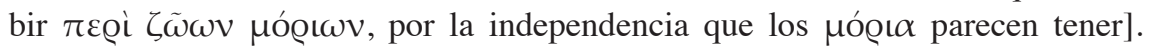
Prescindiendo pues, de esto, no tiene sentido pensar asignar a la esencia una parte, o región en la cosa. No tiene sentido preguntar por el órgano del pensa- 
miento, o del sentir. Piensa o siente el hombre entero. La esencia transciende, o se trasfunde toda por toda la cosa: carácter transfuso de la esencia.

$4^{\circ}$. Al estar toda en toda la cosa no se agota en sí misma la esencia. Al revés de las cosas. Si el vino estuviera todo en todo el cuerpo del bebedor, el vaso estaría vacío, en cambio, es en sí y por sí a pesar de no existir más que en las cosas. La esencia está toda en una cosa en la medida en que está en sí misma. Este es uno de los más graves problemas de la Metafísica: está en cierto modo en otro en cuanto es en sí. Su ser es sólo un ser por sí. Es la perseidad. Mas entonces, ¿qué es la cosa?

\section{¿Qué es la cosa?}

La cosa se ha convertido en problema al descubrir la esencia. Sería un error interpretar El Parménides de Platón como un simple problema de esencia; no, hay en él a la vez el problema de la cosa.

$1^{\circ}$. La cosa no puede no tener esencia. Todo lo que es, es esto o lo otro, tal o cual cosa. Si elimináramos la esencia, no tendríamos más que un vacío que indicara el hueco de una cosa, pero no la cosa. Es decir, lo que creemos más tangible y real, si se prescinde de su esencia, sería algo que puede ser todo su ser nada. Sería el no-ser. Hegel dice que los apóstoles, que encontraron vacío el sepulcro de Cristo, no encontraron a Cristo, sino el puro "Dieses". La cosa es el

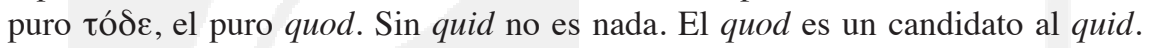
Es el problema del no ser como siendo, que corre por toda la Filosofía griega. La cosa no puede ser sino teniendo alguna esencia, es decir, siendo algo, aliquid.

$2^{\circ}$. Esto no sólo es así en parte por adición externa de una esencia a la cosa, sino que es ser constitutivamente. La cosa es constitutivamente un ser esto o lo otro. No es que haya primero cosa, segundo, esencia y tercero, copulación, sino que cada cosa es la interna extensión a apropiarse tal o cual esencia. Platón llamó a esto "participación”, $\mu \varepsilon \dot{\theta} \theta \varepsilon \xi ı$. Más aún, no llamamos cosa sino a aquello que tiene esencia. Mientras que al principio eran las cosas quienes tenían esencia, ahora son cosas quienes tienen esencia. La pregunta de Parménides a Sócrates, ¿de qué cosa hay esencia?, no se refiere tanto a la esencia, cuanto a la cosa misma. De las privaciones y negaciones, etc., no hay esencia; por tanto no son propiamente hablando cosas. Algo es una cosa en la medida que posee una esencia. Esto lo expresamos diciendo que frente a una esencia que es ab-soluta, toda cosa es relativa, relativa a su esencia.

$3^{\circ}$. Esta relación no es una pura correlación formal. El modo de relación consiste en que la cosa es el "sujeto" de la esencia. Toda cosa es "subjetiva", útoќ́ıน cia, pero este tener es tenerla como sujeto, no un simple contenerla. 
$4^{\circ}$. La cosa como sujeto está "sujeta a...", y esta sujeción del sujeto es algo

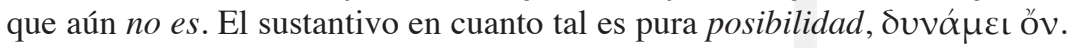

$5^{\circ}$. Por tener la esencia alteridad, la cosa es sujeto, pero sujeto de alteración. Está sujeta a alteración, esto es, es alterable.

En conclusión, saber no es discernir, sino decir qué es y éste es decir más, es la esencia que tiene la cosa. Tal es la definición.

En qué consiste la mente qua alter.

¿Qué es la mens, el voũs? Es ante todo una actividad, a diferencia del ver que es pura pasividad. Diferencia entre la absorción del que está "concentrado" y del "niño". ¿Qué hace la mente en su actividad? La mente no hace las cosas. Tampoco hace su esencia. Tampoco hace la "unión" (llamémoslo así) de esencia y cosa: el algo. Así pues, en rigor, hacer la mente no hace nada. No es sujeto de un facere, sino de un agere. Por esto podríamos decir que la mente es actuosa mejor que activa. ¿En qué consiste este agere? Consiste en un dar a conocer las

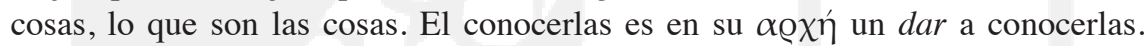
Si se quiere emplear el verbo hacer: la mente no hace las cosas sino su verdad. El problema de la verdad no está en la ecuación o inecuación consecutiva de la cosa y de la representación, sino en este primigenio dar.

\section{¿En qué consiste la mismidad, el ser-expreso?}

Índole de este $d a r$. ¿A quién $d a$ este dar? La mente se da a conocer las cosas, "se", a sí misma. La visión de las cosas en que pudiera consistir la verdad no será una simple visión que se tiene, sino una visión que se da. Claro, no hay que tomar este "se" como si previamente existiera la mente ocupada consigo misma y además se dieran a conocer las cosas. No, sino que al constituirse la verdad de las cosas es cuando se constituye el "se" en su forma actual, la mente en su forma actual. ¿En qué sentido la mente se $d a$ a conocer las cosas? ¿Cómo es la mente expresión de las cosas? En dos sentidos:

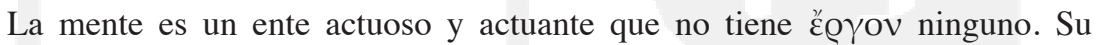

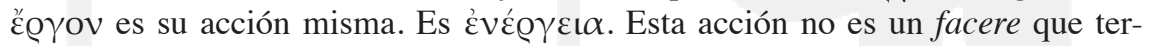
mina en un factum, sino un agere que termina en un actum. [La acción termina en sí misma: es inmanente]. La mens expresa las cosas por ser la forma superior del ser, como cuando decimos que fulano es la expresión viviente del poeta, o del político. Entendemos que la poesía, o la política se realizan en él de modo supremo y ejemplar. Para un griego la mente es la expresión suprema del ser porque ser es ser suficiente y absoluto y sólo lo es el ente cuyo ser es actividad inmanente (v. Parménides, Fragmentos) y suficiente.

La mente no es expresión del ser por ser el ente por excelencia, tiene la índole misma de su acción, por su modo de actuar. Aunque esa acción termina en 
la mente misma, consiste en que se actúan las cosas. ¿En qué consiste esta actuación? No es rigurosamente hablando una actuación. Cuando decimos que con la acción y por la acción de la mente se actúan las cosas, no queremos decir que sin mente los cuerpos, por ejemplo, no actúan los unos sobre los otros. Los cuerpos actúan entre sí sin mente. Ni es que sea esta actuación una actuación sobre sí mismos: ningún cuerpo puede actuar sobre sí mismo (y en esto consiste justamente su corporeidad). Tampoco es una actuación de las cosas sobre la mente; y esto por varias razones, entre otras, dos:

Porque las cosas actúan sobre el hombre de mil maneras. Entonces esta actuación es un huero formalismo que oculta el problema en lugar de resolverlo, al igual a como ocultaba el concepto de "relación" (huero formalismo), el problema de la verdad. Las cosas pueden actuar físicamente, o sobre el deseo, etc. Lo interesante es saber cómo cierta actuación es un darse a conocer.

Porque lo esencial es esto, darse a conocer y no la actuación. Lo segundo es resultado de lo primero. Por eso mejor que decir que las cosas actúan en la mente, diríamos que se actualizan en ella, se hacen actuales - "dejan sentir su ser" - "se dan a conocer". [En ese dar a conocer las cosas, las cosas se dan a conocer en su ser. El ser es entonces la actualización de la cosa]. ¿Cómo es posible esta actualización? Oĩov tò $\phi \tilde{\omega} s$, dirían Platón y Aristóteles, como la luz. La luz hace actual el color. Para los griegos, los colores existen aun en la oscuridad; la luz sólo los hace "actuales". Pero además, la luz es una (čv) luz en que los cuerpos todos están reunidos en la unidad de un panorama. La luz lo baña y

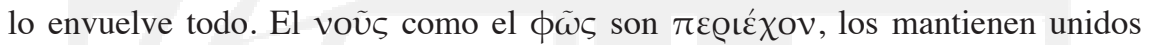
(Parménides). Gracias a esta luz se ven las cosas. Un griego diría que la luz no se ve (en el mismo sentido en que se ven los colores), no se ve pero hace ver.

No se ve la luz, sino las cosas. Un espacio vacío sin más que luz, no sería visible. La luz es un ente actual que consiste en hacer ver las cosas sin ser visto

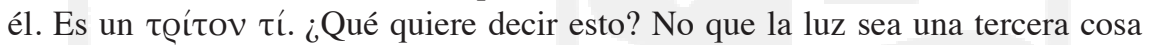
junto a la cosa vista y a la mente. Sino que tiene un tercer modo de ser: ni es cosa, ni ó@үavov de visión que sin ser visto hace ver: hace visibles las cosas y

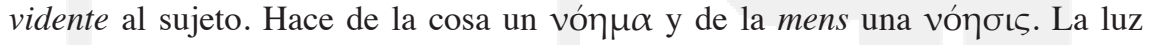

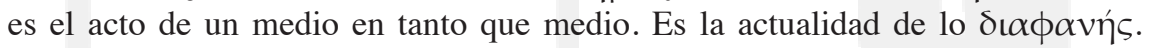
Este es el único sentido de la mismidad de la mente y las cosas. Una mediación,

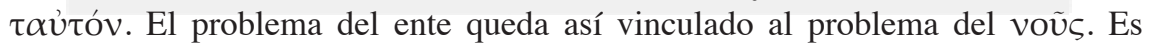
imposible responder al uno sin co-responder al otro. El esse y el nosse 6 íntimamente unidos. Vamos a precisar un poco la índole de esta acción actualizadora.

Según acabamos de ver, la mente es ante todo medio; activando actualiza. No es cosa. No solamente actualiza, sino que esta actuación consiste en actuali-

6. El ser y el conocer. 
zarse y actualizar. Decimos que hay actualmente luz cuando son las cosas visibles. El voũ consiste en actualizar. Su presunta inmanencia, la actualización de la mente por sí misma, es co-resultado de la actualización de las cosas. La mente se constituye en el momento y en la medida en que se constituye lo que no es la mente. La inmanencia, resultado de la transcendencia. Esta es condición de toda inmanencia.

La mente se actualiza y actualiza en cada caso, en cada cosa. Podría parecer que al actualizarse crea, por así decirlo, un vacío ámbito de actualización dentro del cual surgieran en una manera u otra las cosas actuales, no. Esto creyó Hegel. Un grave error. En el actualizarse la mente se actualiza en cada cosa: es ahora esto, luego lo otro. "No encontrarás la mente sin la cosa en que se expresa concretamente" (Parménides). Puede decirse que las cosas se expresan en el voũ pero también el voũ en las cosas $=\pi \varepsilon \phi \alpha \tau \iota \sigma \mu \varepsilon ́$ vov $^{7}$.

Esta actuación de la mente no es un simple estar en acto. Es un actuar en sentido activo y actuante. Quien está en acto es la cosa actualizada. La mente también está en acto en cierto modo, pero como sin estar actualmente actuando. Es el voũ como actividad. ¿Cómo actúa la mente? En la luz las cosas lucen. Gracias a esta índole relucente de la luz, teníamos un solo acto, según el cual toda luz es luz de una u otra cosa. Lo que de las cosas hay en la luz en tanto que relucente, es pura relucencia. No es la relación genitiva de la esencia, sino una estructura, o relación de relucencia. El actuar es estar reluciendo. No es que primero haya mente para sí, segundo cosas, y luego unión, sino que la actualidad de la mente es la misma que la actualidad de las cosas. Este es el único sentido de la mismidad. Gracias a esto, además de haber una cosa, una esencia de vino y algo que es vino, este algo, gracias a la luz o lumen, adquiere una sutil "cualidad": el "brillo" o la claridad, que permite que veamos efectivamente la cosa. La luz no da a la cosa el color, pero sí su claridad, o brillo. Hay un sutil desdoblamiento entre la cosa en cuanto tiene tal color y el color reluciente. No es una distinción real, ni física, ni numérica, ni metafísica, como la de esencia y cosa. La luz confiere a la cosa esa actualidad luminosa y espectral que el griego llamó

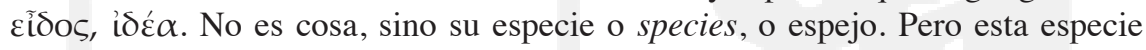
no está en la cosa, sino en la luz misma. Es la luz que se irradia y refleja sobre el objeto y dibuja en otro sitio su "especie". La mente ve la cosa a fuerza de escoger esa especie de la cosa, esa su película brillante. Conocer es un engendrar la idea en la mente. No tenemos sólo la visión de la cosa, sino su especie, o idea.

Esta recolección luminiscente no es un pasivo recibir la luz del objeto. No es un simple recoger, sino es un "hacer", una generación. Al recoger la mente la especie brillante del objeto, se va diciendo lo que es la cosa. Sobre su brillante especie, la mente ve la cosa. En esta reflexión ontológica la mente tiene patente

7. Expresado, declarado (de $\phi \alpha \tau i \zeta \omega-$ de la raíz de $\phi \eta \mu$ í, decir-). 
la cosa, pero en su expresión mental. No es que vea primero la expresión y luego lo expresado. Lo que ve es sólo lo expresado, pero lo ve como "expresado" en su expresión. Esta expresión es el concepto o engendro mental. No hay referencia de la mente a la cosa, sino expresión en la cosa. El dar es expresarse la cosa mediante el ser luminescente de la especie. [El concepto tiene la cosa así como "irreal", como "inteligible", pero no como real. Es el concepto objetivo]. Ya veremos por qué no puede el objeto ser sino expresado.

El concepto está pues, en lo que la mente se dice a sí misma de las cosas. A esta recolección llamó el griego $\lambda \varepsilon ́ \gamma \varepsilon \iota v$ : decirse lo que son las cosas = formar conceptos. Verbum mentis lo llamaron los escolásticos. No es una expresión de lo que ya se ve, como cuando decimos que A es B, sino una expresión constitutiva de A en tanto que A. Ver el A es tener su concepto = decirse lo que es. El concepto no es sino el término ideal del decir, no su supuesto. En el vov̂s la mente revierte sobre la cosa y ésta sobre aquella. En esta reflexión ontológica las cosas no son sólo razón de vino, sino verdadera razón de vino.

La mente, vô̂ร, no es pues, sólo una substante revelación de la cosa (Parménides), sino una actividad que no logra ver más que recogiendo y separando. Las cosas tienen tensa a la mens, la cual en esa su distensión entiende. El voũs

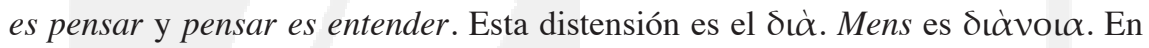
esa distensión las cosas se mantienen distintas, o unificadas. La unidad de los colores rojos existe sólo en la luz que los ilumina. Al ser verdaderas las cosas se actualizan en géneros y diferencias, y especies. Decir que una cosa es esencia de vino, es decir que la esencia del vino está presente a la cosa. La $\mu \varepsilon \dot{\theta \varepsilon \xi \xi \varsigma ~ p a r a ~}$ Platón se resuelve en iluminación, oĩov tò $\phi \tilde{\omega} \varsigma$. A esto es a lo que los griegos llamaron $\lambda$ ó $\gamma O \varsigma$ propiamente dicho. Y su $\lambda \varepsilon \gamma o ́ \mu \varepsilon v o v$ es la ratio. $\Lambda$ ó $\gamma O \varsigma=R a-$ tio. Dar a conocer las cosas es dar razón de ellas.

\section{Del segundo inédito: Categorías filosóficas (1933)}

\section{Influencia de esta idea de sustancia}

$1^{\circ}$. En Física: estructura del átomo. $2^{\circ}$. En Matemáticas: el infinito pequeño.

El conjunto. $3^{\circ}$. En Ciencias: La química biológica. $4^{\circ}$. En Psicología: El yo. $5^{\circ}$. En Historia: El “anthropos”. $6^{\circ}$. En Teología: Experiencia religiosa

Para nadie es secreto que la física ha nacido de una idea de la sustancia. Por eso su problema es el átomo. La idea de sustancia ha tenido un éxito en física hasta que se ha sentido interceptada con la elaboración de la idea sustancia como cosa material.

Cabría descubrir en las ciencias la idea de un positum como sustancia que constituyese la trabazón de su saber. El cálculo infinitesimal de Leibniz nació de considerar la sustancia integrada por seres infinitamente pequeños. Análogamente la biología se constituyó como ciencia positiva cuando intenta resolver la vida 
en entes sustantes. La vida no se ha tomado nunca desde otros puntos de vista. Las dificultades que halla la historia para su ciencia se reducen a la dificultad con que toparon los griegos al querer considerar su objeto como sustante. La historia está compuesta por individuos combinados. El substratum de las historias es la sustancia.

En definitiva, podríamos mostrar que todas las ciencias se han constituido a base de la idea de sustancia, y su crisis es la de la idea de sustancia. Porque se podría pensar que la crisis de la ciencia positiva es una crisis de método. Parece como si la física actual no hubiese tropezado con el mismo órgano con el que tropezó la física del s. XVI. El fracaso de la ciencia positiva estriba en haber aplicado métodos análogos a los físicos a entes que en modo alguno pueden ser tratados de ese modo. Se trataría de que otras ciencias no traten la sustancia en el mismo sentido en que lo trataba la física. Dejar a las cosas estar ahí y que sean lo que sean no es sino conocerlas. La crisis de la ciencia moderna será pues, la crisis del conocimiento.

Ahora bien. El conocimiento sólo es la expresión de lo que ve un hombre... Es el científico el que hace el conocimiento. El conocimiento radica en el hombre que conoce. Y esta es la innovación de Heidegger. No se trata en la ciencia de un reflejo de las cosas, sino de un modo de existir el hombre en el universo. La idea de la positividad está en crisis. Desde Aristóteles ha venido diciéndose que el único modo que tienen las cosas de estar puestas ante el hombre es la sustancialidad. ¿Qué significa esta ingente identidad entre el positum y la sustancia? La sustancia es el correlato del dejar estar ahí: ser, dejar estar ahí. ¿Y si esto no fuera verdad para las cosas que están ahí? Para Heidegger existen los existenciales. La historia se forma no con categorías, sino con existenciales. La existencia del hombre, que es histórica, no consiste en estar ahí, sino en resolverse a ser ella lo que es. No puede por tanto reducirse la investigación de los modos del ser a la investigación de las categorías.

En segundo lugar, veíamos que el positum de la ciencia es un positum que acontece en alguna parte. Kant se hacía cuestión de este dónde. Pero decía que se hallaba en la naturaleza junto a la cual descubre la región del espíritu, pero a esta región le ha negado el carácter científico. Se ha hecho cuestión de que el ser se estructure en regiones del ser. La crisis de la ciencia positiva no es una crisis de métodos: es que se ha tomado de una manera pasiva la idea de sustancia que consiste en estar ahí, sin tener en cuenta que es posible que los entes sustantes estén puestos en regiones distintas. Así acontece que por ejemplo la matemática no tiene idea de lo que ella es, y de en qué región se encuentra. La lucha entre el intuicionismo [y el formalismo] ${ }^{8}$ es una lucha ontológica. La seguridad de la

8. En los apuntes hay un espacio en blanco, donde posiblemente Zubiri aludía al formalismo. 
ciencia estriba en que sepa dónde está. La filosofía se ha visto afectada también por esa idea de la sustancia. El creer que el ser es una cosa sutil más. Platón hizo de las ideas cosas separadas. La teología católica las convirtió en pensamientos de la sustancia divina. Descartes, en afecciones de la sustancia pensante. En Kant el yo no es sustancia, pero el compuesto yo más cosas es una cosa más. Sólo Heidegger ha visto que ser no es ser sustancia.

\section{El saber positivo y el metafísico}

Sentido de esta crisis. No es metodológica: dejar estar $\neq$ conocer. Sino el positum: $1^{\circ}$. Das Ganze: la idea de totalidad. $2^{\circ}$. Das werden: Ser $\neq$ estar ahí $\neq$ Nützen ${ }^{9}$. Y esto supone: $1^{\circ}$. El problema de la ontología regional. $2^{\circ}$. El problema del sentido mismo del Ser

El fracaso de las ciencias positivas no es el fracaso de un saber, sino que es algo que afecta a una raíz más honda, al carácter ontológico que tiene el positum de esa ciencia positiva. No se trata de la rectificación de un método, sino de la puesta en crisis de la idea misma del saber. No es la ciencia el terreno donde el problema de la idea de sustancia y su crisis debe tratarse, sino que cada vez es más claro que no es en la ciencia positiva donde nacen los problemas filosóficos, sino que estos repercuten en ella porque emanan de algo más radical. La idea de sustancia ha sido puesta en crisis en el saber positivo en dos dimensiones: (1) La idea de todo positum al que se refiere un cierto saber. (2) La idea misma de la naturaleza en cuanto tal.

Se plantea como primer problema dentro del saber positivo el forjarse una idea del todo. La ciencia positiva ha despachado la idea del todo para atenerse formalmente al detalle concreto, a la particularidad inexorable del saber positivo. Sin embargo, quien pueda sentir la trepidación de la ciencia positiva actual, fácilmente vería que ha puesto en crisis dentro de cada ciencia la idea de la totalidad. Una totalidad que ofrece un carácter peculiar: es una totalidad radical en la que va envuelto el investigador mismo. El más grave problema por el que la física atraviesa es el de la inexorabilidad de las causas que forman el universo. Problema que culmina con la idea de los indeterminados (Heisemberg).

La idea del positum como un ingente ente sustante se hace problema para la ciencia positiva. Pero, en segundo lugar, no se dice que el totum sea uno en toda parte. De ahí, pues, que esta idea de la totalidad lleva aparejado el problema de la estructura de todo cuanto hay en regiones que hay que articular. Se plantea ahora pues, el problema de una ontología regional, de esas regiones en las que puede existir el positum de un saber. El saber positivo creía sólo en una única

9. Palabra difícil de leer en la papeleta de Zubiri. Podría ser la transcrita, que significa útil, provechoso. 
totalidad, la naturaleza. Podría ver cómo el pensamiento de la unidad regional de cuanto es ha gravitado sobre las ciencias, que podían haberse hecho cuestión de la región en que se mueven. De ahí el intento llevado a cabo en el siglo XIX para crear ciencias puras.

En ese momento es cuando se agudiza el problema que encierra la pregunta formulada por el hombre que pasa de las sombras a la realidad. Si ahora resulta que el ser se halla articulado en regiones esencialmente irreductibles, entonces el dejar que las cosas estén donde están se hace más problema que nunca. Si esto es así, entonces puede el hombre preguntarse qué es algo, qué es el ser en cuanto tal. Así surge el problema de las cosas y el del ser cuando el hombre ha sentido el último enraizamiento de las cosas en sí.

Comte había dicho que los tres estados (teológico, metafísico y positivo) son tres estados que se suceden en la historia de la humanidad y que se eliminan el uno al otro. El despertar al estado metafísico era una superación del mitológico, y a su vez, el estado positivo constituía la eliminación radical del saber metafísico. Es preciso que nos hagamos ahora cuestión de si tiene sentido que dentro de la actitud [radical] ${ }^{10}$ se halle el hombre escindido en dos posiciones tan distintas como la del saber positivo y el metafísico. La respuesta que el hombre ha dado a esto es que la ciencia tiene tales problemas, que escapan a su función. Habría un ímpetu de la ciencia a ciertas realidades que no pueden ser tratadas... y el hombre no puede más que vagar en esas cuestiones que no ha resuelto. Se trata de realidades sobre saberes positivos, una magna intuición. El saber positivo se halla integrado por muchas leyes científicas, pero es forzoso que una vez siquiera piense el científico por qué el hombre puede dar leyes.

Desde un segundo punto de vista, junto a la idea de una metafísica inductiva que se ha elaborado en muchos centros y que han hecho de ella un soporte de la vida, se ha intentado elevar la metafísica a existencia partiendo, es claro, de un punto de vista distinto. Se trata de una ciencia que descubre leyes con arreglo a un método, pero que no se hace cuestión de ellas. Cabe pensar en una ciencia de la ciencia. Como teoría de la ciencia o la teoría del conocimiento, ha vivido la metafísica apelando a un neokantismo. En definitiva, lo más opuesto a toda novedad. Una interpretación hecha desde el punto de vista de la teoría del conocimiento es insuficiente porque parte del supuesto de que el conocimiento brota y marcha de sí mismo. Porque si bien es cierto que en él ocurre la verdad de las cosas, el hombre está en una relación con ellas que califica de veritativa. El hombre vive en verdad. Por eso, no es que el conocimiento sea el modo de dejar que las cosas estén ahí, sino que porque las cosas están ahí existe el conocimiento. Si existe un modo de saber distinto del positivo necesita un modo de estar con las cosas anterior a que éste se exprese en un conocimiento.

10. En el original hay un hueco. 
Al salir de la caverna el hombre ha vuelto la mirada sobre las cosas que no son el ser o la nada. El hombre, cuando despierta a la vida teorética, pregunta por las cosas, pero cuando ha querido responder a su pregunta, se ha visto perdido entre las cosas, ha rebotado sobre ellas para hacerse cuestión de qué sentido tiene su pregunta sobre las cosas en cuanto son.

La historia de la metafísica desde Parménides hasta Platón no es la historia del ser. El saber de Parménides es algo especial que no es metafísico, pero tampoco positivo. Si a Parménides se le preguntara por qué el mundo es esférico, no se le hubiera ocurrido experimentar sobre él para demostrarlo, sino que hubiese apelado a otras razones.

El momento metafísico de la concepción del universo no depende de que la metafísica se haya dirigido al ser, sino que se ha dirigido a las cosas. La metafísica ha sido el acceso a las cosas. Y ha hecho falta que este método vaya acompañado de un fracaso para que el hombre se repliegue y pregunte en qué consiste el que las cosas estén donde están.

En el choque del hombre con las cosas hay dos momentos. Al chocar el hombre con las cosas se repliega sobre sí mismo, y a esto es a lo que desde Aristóteles a Hegel ha venido llamándose momento transcendental. El hombre no podría haber ido a las cosas si previamente no existiera junto a ellas transcendiéndolas. Las cosas sólo se muestran al hombre cuando éste toma una actitud, y la actitud estando sobre ellas crea una existencia transcendente. Transcender significa pura y simplemente el hecho de que para descubrir cada cosa el hombre necesita estar allende todas ellas, transcendiéndolas.

Pero más difícil que descubrir las cosas es descubrir lo que el hombre es.

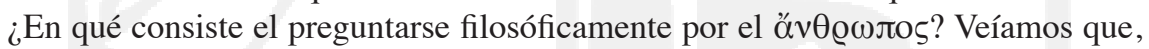
al reflejarse el hombre sobre su actitud, ésta es algo bien sencillo. Al entender su actitud, el hombre ha co-entendido que aquello que va a entrar en ella es algo que está ahí. El entender su actitud es coentender el ser de las cosas que son. Por tanto sería igual su ser que el de las cosas que son. El sentido del ser es el problema de la actitud humana que lo descubre. Por eso pudo el hombre griego llevar una vida teorética: porque le iba en la idea del ser la existencia de su propio espíritu.

Hay que volver a Comte. Los tres estados no significan tres estados sucesivos que se excluyen entre sí, sino que se implican mutuamente no de un modo cronológico sino esencialmente. Son congéneres y coetáneos. Arrancan de algo que califica la interna libertad de la existencia humana. Donde libertad es el hecho de que cada actitud sólo puede ser adoptada por la liberación de la anterior, que no desaparece sino que queda como el fondo del que siempre se está liberando.

El saber positivo, a fuerza de ir a las cosas, ha perdido el sentido de ellas. $\mathrm{Si}$ es verdad que la ciencia positiva se constituye reflejando lo que el mundo 
es, ¿por qué se experimentan unas cosas en una época y no otras? Ninguno de los tres estados tienen sentido si no conducen todos al ser. Si es verdad que los tres se sostienen, la madurez plena del saber no se adquiere sino en el saber del positum de que las cosas son. Cuando la metafísica prende al hombre, se ha de convertir en problema el modo de volver a las ciencias positivas. La catástrofe del idealismo alemán es el haberse hecho una ciencia del ser. La filosofía ha sido la ciencia de las cosas en cuanto que son.

¿Cómo la filosofía no trata del ser y habla de las cosas que son? El problema de la filosofía estriba justamente en que, siendo distintos el ser y las cosas que son, es sin embargo el mismo ser. Pero lo esencial es ese de en el ser de las cosas. No es lo grave del positivismo lo que tiene de saber positivo, sino el creer que reposa sobre sí mismo. En realidad, la ciencia positiva actual es un caudal de conocimientos, pero no constituye una vida teorética porque es algo muy distante de la verdad del descubrimiento de la verdad positiva. Sólo cuando la ciencia es el ejercicio de una vida teorética tiene un sentido. El saber metafísico se ha articulado al rebotar el hombre sobre las cosas para entrar en sí mismo, pero en esa entrada el hombre se siente privado de las cosas, y la privación es el impulso para ir a las cosas que faltan. Atracción del abismo. El hombre ha ido hacia las cosas atraído por ellas cuando se le han ofrecido en su radical nihilidad que experimenta al entrar en su realidad transcendente. Y esta fuerza es el entusiasmo a raíz de la vida teorética.

El entusiasmo no es un sentimentalismo que transita sobre la existencia del hombre, sino que en él acontece algo más fundamental. Atraído el hombre por las cosas, al ir a ellas va porque él mismo existe. El hombre es el ser más triste del universo, no le basta con existir, necesita ir a las cosas que son porque su ser está condicionado por ellas. Se siente arrastrado por ellas hacia ellas. En el entusiasmo fuerza el hombre su propio ser, es nada menos que la pasión de ser. Se quiere interpretar esta pasión como la necesidad de la existencia de un pueblo en un universo, pero esto es idiota ${ }^{11}$.

En el entusiasmo el hombre se siente atraído por las cosas, no por una curiosidad. El hombre va las cosas, pero este ir puede llevar consigo una tragedia interna, y es el olvido de todo aquello que ha necesitado para ir a ellas. Se puede encontrar tan cómodo dentro que olvida que va a las cosas porque su existencia es transcendente. Este olvido radical es la pérdida del sentido. El entusiasmo se ha convertido en orgía. A cualquier azar se confiere el rango de un saber positivo. Bastaría con que el hombre estableciera categorías en el universo (hay

11. Posiblemente, Zubiri alude de nuevo al texto de Heidegger ya citado: La autoafirmación de la universidad alemana (discurso de Heidegger con ocasión de su toma de posesión como rector de la Universidad de Freiburg, el 27 de mayo de 1933, Die Selbstbehauptung der deutschen Universität, Breslau, 1933). 
categorías de verdad) para que la ciencia no ofreciera ese aspecto orgiástico y caótico. Contra la orgía no hay más que la virtud que movió al hombre en el entusiasmo. El entusiasmo nació de la pasión de ser, y origen de toda pasión es la austeridad, la huida de las cosas.

Volver a adquirir el sentido de lo que hace la ciencia positiva significa sencillamente colocar las cosas en su lugar. La ciencia positiva no sólo ha vivido la orgía, sino también la utopía de las verdades. Ninguna verdad parece saberse a sí misma en el orden de las verdades, en el mundo en donde todas las verdades se hallan en una continuidad ordenada. Entonces quedaría patente que la orgía del saber positivo no ha sido un azar, sino que tenía que venir forzosamente por la pérdida del sentido del lugar donde va a alojar las cosas: ¿En el yo pensante? ¿En Dios? Se convierte en problema para la ciencia positiva el lugar donde las verdades habitan. Pero las verdades no son cosas, sino el descubrimiento que hace el hombre de ellas. Por eso su descubrimiento es el del lugar que el hombre ocupa entre las cosas.

El conocimiento filosófico tiene que buscar el lugar donde el hombre y las cosas existen. La filosofía brotó de una entrega entusiástica a las cosas. La filosofía no consiste pura y simplemente en despertar al ser. Ninguna pasión, modo radical del ser humano, ha existido sólo por despertar. El problema consiste en saber mantenerse dentro de ella. La filosofía no vive sino de una perenne declaración de amor que convierte en problemático lo que esencialmente es.

\section{$* * *$}

\section{Una palabra final}

A la lectura de estos dos inéditos del Zubiri joven, habríamos de observar con satisfacción cómo Ellacuría, en diálogo con su maestro - diálogo que duró 25 bien apretados años - , iba a tener la experiencia de ver desarrollado el sistema metafísico que definitivamente denunciaba tres asuntos de la actividad del hombre occidental en su lucha por encontrar el qué de esa realidad que nos afecta. Tres asuntos que en formulación zubiriana podríamos glosarlos como la deslogificación de la inteligencia, la desentificación de la realidad y la desobjetivación de Dios.

Aprendió bien la lección Ignacio Ellacuría, y ahí está su propio legado que yo describiría para terminar. Primero, su originalidad en el planteamiento de la historia como nota que se actualiza en el modo de quedar la realidad como formalidad en la mente humana. Segundo, haber analizado la situación de la realidad mundanal, que le tocó vivir, desde la perspectiva zubiriana del ser humano, creador incesante de posibilidades para la transformación de nuevas formas y modos de vida, que reconfiguren constantemente en libertad los sistemas sociales de convivencia. Y tercero, haber sabido redescubrir para la vía teológica, el 
topos, el lugar donde la revelación del Dios cristiano se encuentra "de-positada": aquella expresión evangélica de que "a los pobres los tenéis siempre con vosotros" (Mt 26, 11). El actualizar desde aquí la presencia del Dios cristiano creo que ha sido la mejor contribución de Ignacio Ellacuría a eso que entiendo que ya entre nosotros es todo menos "tópico", la así llamada Teología de la Liberación. 